\title{
Could We Do Better in the Administration of "Justice" to Neurological Patients?
}

Can J Neurol Sci. 2012; 39: 563

Aphorisms (from the Greek aphorismós - meaning definition) are short pithy sayings that can be remembered easily and convey a particular truth in a few words. An example would be the familiar saying "Justice delayed, is justice denied"attributed to the British politician William Gladstone (18091898) ${ }^{1}$. More recently, stroke neurologists have popularized the saying, "Time is brain" stressing the critical importance of starting treatment with tissue plasminogen activator (tpA) as early as possible. In this month's edition of the Canadian Journal of Neurological Sciences, Peter Hughes and Alan Jackson ${ }^{2}$ from the University of Manitoba show that "justice" is often being "denied" to patients with possible Herpes simplex encephalitis and they raise the concern that this is probably not good for brain tissue.

Until the late 1970s, encephalitis represented what we might consider a "classical" neurological disorder. One could localize the lesion, and make the clinical diagnosis but there was no treatment and therefore, no pressure to get on with the specific diagnosis apart from ruling out a treatable mimic such as bacterial meningitis. Then, in 1977 Whitley et $\mathrm{al}^{3}$ reported that the treatment of biopsy-proved Herpes simplex encephalitis with adenine arabinoside could reduce the mortality from 70 to 28 per cent with excellent functional outcome in over 50 percent of the survivors. Now the pressure was on! We had a treatment for Herpes simplex encephalitis and it was incumbent on the clinician to make the diagnosis in a timely fashion so that treatment could be instituted. Further improvements in our ability to treat Herpes simplex encephalitis were realized with the introduction of acyclovir. In 1997, McGrath et $\mathrm{al}^{4}$ reviewed the outcome of patients with Herpes simplex encephalitis. They found that treatment with acyclovir was associated with death or severe neurological disability in 30 percent of patients. They also found that the remaining 70 percent of patients were not "home free". Even though they regained independence, most of the survivors had persistent neurological signs, symptoms or both. The final sentence in their paper reads: "Further reduction of the mortality and morbidity of herpes simplex encephalitis in the future may be achieved with longer courses of treatment and new antiviral agents, but a key aim in improving the outcome should be a reduction in unnecessary delays in diagnosis and treatment [emphasis mine]."

Despite the 2008 guideline by Tunkel et $\mathrm{al}^{5}$ indicating that acyclovir therapy can be started on the basis of clinical suspicion of encephalitis before confirmatory testing is available, Hughes and Jackson found that acyclovir was initiated a median of 21 hours (3-407) after presentation with encephalitis. Of note is the fact that the most common reason for delay was failure to consider Herpes simplex encephalitis in the differential diagnosis despite suggestive clinical features. Another cause for delay was waiting for the results of the cerebrospinal fluid examination.
The French author Henri-Louis Bergson (1859-1941) observed: "The eye sees only what the mind is prepared to comprehend." 6 Like many things in medicine, if you don't think of the diagnosis you don't add it into your differential. Clinicians usually know what to do when they think of the diagnosis but when they don't think of it, as in the case of encephalitis, specific treatment is delayed and since time is brain, patients are most probably losing out. Can anything be done to help that situation? Educating people to start acyclovir before doing the lumbar puncture is likely to be helpful. It seems to have made a difference in the way we treat suspected bacterial meningitis. But what about getting people to think of the diagnosis in the first place? Garg et $\mathrm{al}^{7}$ did a systematic review of computerized clinical decision support systems (CCDSS) in 2005 and found that many CCDSS improve practitioner performance. It is to be hoped that as the use of the electronic health record rolls out in hospitals, the CCDSS that are being built into those systems will help the busy clinician-both the learner and the experienced consultant-be better prepared to "see" things and thereby be ready to act in a timely fashion. A sophisticated system that helps create a differential diagnosis based on the patient's symptoms and signs could be a powerful learning tool and assist in ensuring that "justice is swift" and that outcomes are not adversely affected by delay either in diagnosis or in the initiation of therapy.

\section{Paul Cooper \\ London Health Sciences Centre London, Ontario, Canada}

\section{REFERENCES}

1. William Ewart Gladstone (1809-1898). Familiar Quotations - John Bartlett. Justin Kaplan, editor. Boston: Little, Brown and Company; 1992.

2. Hughes PS, Jackson AC. Delays in initiation of acyclovir therapy in herpes simplex encephalitis. Can J Neurol Sci. 2012;39(5):644-8.

3. Whitley RJ, Soong S-J, Dolin R, et al. Adenine arabinoside therapy of biopsy-proved herpes simplex encephalitis-National Institute of Allergy and Infectious Diseases collaborative antiviral study. N Engl J Med. 1977 Aug;297:289-94.

4. McGrath, Anderson NE, Croxson MC, Powell KF. Herpex simplex encephalitis treated with acyclovir: diagnosis and long term outcome. J Neurol Neurosurg Psychiatry. 1997 Sep;63:321-6.

5. Tunkel AR, Glaser CA, Bloch KC, et al. The management of encephalitis: clinical practice guidelines by the Infectious Diseases Society of America. Clin Infec Dis. 2008 Aug;47: 303-27.

6. ThinkExist.com [homepage on the Internet] [cited 2012 Jun 15]. Available from: http://thinkexist.com/quotation/the_eye_sees_ only_what_the_mind_is_prepared_to/13601.html

7. Garg AX, Adhikari NK, McDonald H, et al. Effects of computerized clinical decision support systems on practitioner performance and patient outcomes: a systematic review. JAMA. 2005 Mar;293: 1223-38. 